\title{
Painting
}

\section{Heart Grows Fonder}

Jasmine Saini ${ }^{1}$

\section{Abstract}

\section{Description}

This painting was inspired by one patient's mindfulness practice that he developed to cope with depression of a recent loved one's death. Similar to my family of green thumbs, this patient found catharsis in cultivating his late wife's garden of fruits and vegetables after her death. Through mental health practices such as meditation and exercise, a person has a chance to process and heal from difficult circumstances.

\section{Keywords}

psychiatry; mindfulness; art; meditation; adaptation; psychological adaptation; paintings

\section{Conflicts of Interest}

The author declares she has no conflicts of interest.

\section{Author Affiliation}

1. Edward Via Virginia College of Osteopathic Medicine
Author affiliations are listed at the end of this article.

Correspondence to:

Jasmine Saini

(jsaini@vt.vcom.edu) 
HCA Healthcare Journal of Medicine

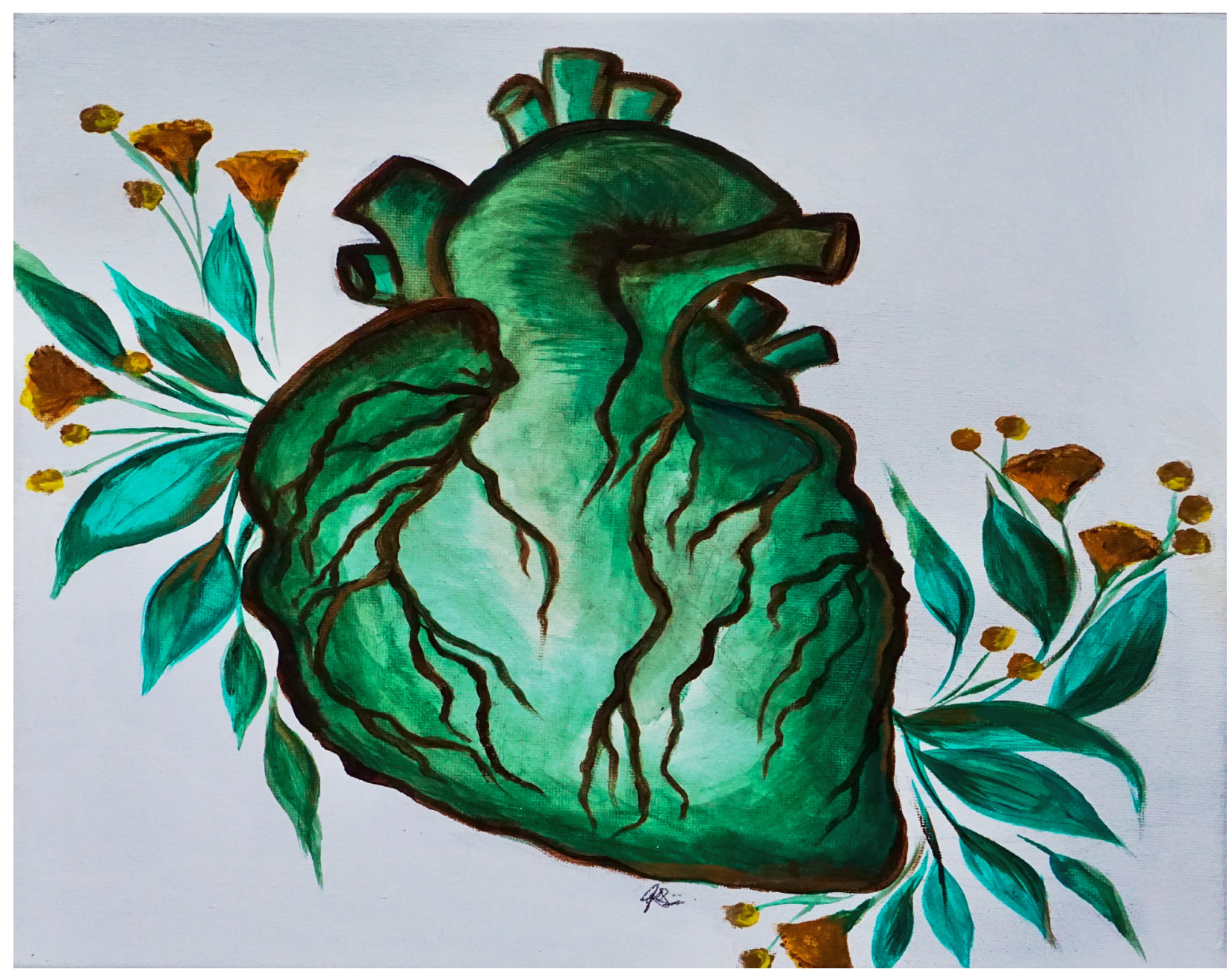

